\title{
Veno-Venous Extracorporeal Membrane Oxygenation Use in Acute Respiratory Distress Syndrome after Acute Stanford Type A Aortic Dissection Repair: A Case Report
}

\author{
Sofia Fernandes, M.D.1*, Maria Ribeiro, M.D ${ }^{1}$, Mariana Rodrigues, $M . D^{1}$, Ricardo Ferreira, \\ $M . D^{2}$, Catarina Barreiros, M.D ${ }^{1}$, Hugo Côrte-Real, M.D $D^{2}$ and Ângelo Nobre, M.D \\ ${ }^{1}$ Department of Anesthesiology, Santa Maria Hospital, Portugal \\ ${ }^{2}$ Department of Cardiothoracic Surgery and Intensive Care Cardiothoracic Surgery, Santa Maria Hospital, Portugal
}

\begin{abstract}
Acute respiratory distress syndrome (ARDS) after acute aortic dissection repair is a serious complication and poses a major challenge. Extracorporeal membrane oxygenation (ECMO) in cardiac surgery has been established for cardiogenic shock refractory to conventional therapy. Veno-venous ECMO can be a rescue modality for ARDS post cardiac surgery.

We present the case of a 73-year-old woman who was referred to our hospital with the diagnosis of acute Stanford type A aortic dissection to receive surgical treatment. She was subjected to successful aortic repair and evolved with severe ARDS, requiring VV-ECMO, which was weaned after 11 days.
\end{abstract}

VV-ECMO can be considered as a treatment option for severe acute lung injury after surgery for aortic dissection.

Keywords

Aortic dissection, ARDS, VV-ECMO

\section{Introduction}

Acute Stanford type A aortic dissection is a life-threatening condition, associated with significant morbidity and mortality $[1,2]$. Emergent surgery is the recommended treatment and is lifesaving for most patients, but it is frequently associated with significant complications and organ dysfunction in the postoperative period, such as acute respiratory distress syndrome (ARDS), a pulmonary condition that can lead to rapidly progressive respiratory failure $[3,4]$.

There are many contributing factors for the development of ARDS after emergent cardiac surgery, namely the severe systemic inflammatory response associated with extracorporeal circulation, surgical trauma, ischemiareperfusion injury upon aortic unclamping, allogeneic blood product transfusions, temporary cardiac dysfunction and systemic hypothermia [5-8]. Management includes the implementation of a protective lung ventilation strategy, strict fluid balance, and early use of neuromuscular blockade. However, for severe ARDS, these measures are often not enough.

In this setting the use of veno-venous extracorporeal membrane oxygenation (VV-ECMO), a form of mechanical circulatory support and extracorporeal life support system, has emerged as a valuable rescue therapy in refractory medical management to facilitate respiratory recovery. Its value is particularly significant in the postcardiotomy scenario considering that some of the most frequent approaches, such as prone positioning, are potentially dangerous.

Contrary to veno-arterial (VA) ECMO, VV-ECMO does not offer hemodynamic support in case of cardiovascular dysfunction. However, when pulmonary dysfunction is present it's a valuable strategy, allowing proper oxygenation and carbon dioxide removal, without some of the disadvantages of VA-ECMO: Increased risk of stroke, bleeding, renal failure

*Corresponding author: Ana Sofia dos Santos Silva Fernandes, Department of Anesthesiology, Santa Maria Hospital, Lisbon, Portugal; Tel: 00-351-217-805-000

Accepted: August 28, 2021

Published online: August 31, 2021

Citation: Fernandes S, Ribeiro M, Rodrigues M, et al. (2021) Veno-Venous Extracorporeal Membrane Oxygenation Use in Acute Respiratory Distress Syndrome after Acute Stanford Type A Aortic Dissection Repair: A Case Report. J Cardiothorac Surg Ther 5(1):98-102 
Citation: Fernandes S, Ribeiro M, Rodrigues M, et al. (2021) Veno-Venous Extracorporeal Membrane Oxygenation Use in Acute Respiratory Distress Syndrome after Acute Stanford Type A Aortic Dissection Repair: A Case Report. J Cardiothorac Surg Ther 5(1):98-102

and Harlequin syndrome (selective lower body oxygenation with upper body hypoxemia).

The available literature regarding the use of VV-ECMO in ARDS after aortic dissection is limited at the moment [9-12].

We report a successful VV-ECMO case as a rescue strategy after aortic emergency surgery in the management of severe ARDS in a patient who presented with acute Stanford type A aortic dissection.

\section{Case Presentation}

A 72-year-old female patient, with a history of ischemic and hypertensive cardiopathy (acute ST elevation myocardial infarction in 2016), type 2 diabetes mellitus, obesity (80 kg, $160 \mathrm{~cm}$, body mass index of $31.25 \mathrm{~kg} / \mathrm{m}^{2}$ ) and hyperuricemia, was admitted to a secondary care hospital (Centro Hospitalar do Oeste, Torres Vedras, Portugal) on June $11^{\text {th }} 2020$ with epigastric pain, fear (angor animi) and palpitations.

On admission, physical examination revealed an oxygen saturation of $88 \%$ at room air, dyspnea and hypoxemia and hypocapnia at arterial blood gas evaluation; hemodynamic assessment exhibited a normotensive profile (systolic blood pressure in the range of $110-125 \mathrm{mmHg}$ ) and a normal sinus rhythm with a heart rate of 70 beats/minute. There were no signs of myocardial ischemia on the electrocardiogram.

A computed tomographic (CT) thoracic angiography (Phillips ${ }^{\circledR}$ Brilliance 64; intravenous Iomeron $^{\circledR}$ contrast) was performed to exclude pulmonary embolism, revealing an acute Stanford type A aortic dissection (Figure 1). She was subsequently transferred to a tertiary university hospital (Hospital de Santa Maria, Centro Hospitalar Universitário Lisboa Norte, Lisbon, Portugal) on the same day, hemodynamically stable, to receive adequate surgical treatment.

On arrival, the patient was still hemodynamically stable, with no signs of respiratory discomfort or neurological alterations. Her arterial blood gas $\left(\mathrm{FiO}_{2} 0.4\right)$ was $\mathrm{pH} 7.49$, $\mathrm{PaCO}_{2} 36 \mathrm{mmHg}, \mathrm{PaO}_{2} 107 \mathrm{mmHg}, \mathrm{HCO}_{3} 27 \mathrm{mmol} / \mathrm{L}, \mathrm{BE} 4.3$ $\mathrm{mmol} / \mathrm{L} ; \mathrm{SaO}_{2} 94 \%$. A complete blood count showed Hgb 10.2 $\mathrm{g} / \mathrm{dL}$; Htc $32.1 \%$; platelet count $158.000 / \mu \mathrm{L}$; activated partial thromboplastin time (aPTT) 27.0/29.0 seconds; International Normalized Ratio (INR) 1.2; fibrinogen $241 \mathrm{mg} / \mathrm{dL}$; serum creatinine $1.38 \mathrm{mg} / \mathrm{dL}$; and troponin T (cTnT-hs) $164 \mathrm{ng} / \mathrm{L}$.

Intraoperative transesophageal echocardiography (Phillips ${ }^{\circledR}$ Epiq 7G; X7-2T probe) revealed an enlarged ascending aorta ( $47 \mathrm{~mm}$ ) with intimal hematoma, descending aorta dissection, small pericardial effusion and depressed biventricular function. Intimal entry point was observed to be in-between the left subclavian and lusory arteries, which was confirmed during the operation.

An ascending aorta and hemi arch aortic replacement with a woven polyester vascular graft $(28 \mathrm{~mm})$ was carried out. Surgery was performed under deep hypothermic cardiopulmonary arrest at 28 으 with selective anterograde cerebral perfusion. Extracorporeal circulation with right common carotid arterial and right atrium appendage venous cannulation (Figure 2) was maintained for 127 minutes; aortic cross clamping for 85 minutes and deep hypothermic cardiopulmonary arrest for 55 minutes. Due to distal anastomosis bleeding, reentry in extracorporeal circulation was required to explore the aortic prosthesis. She was transfused with $4 \mathrm{~g}$ of fibrinogen, two platelet concentrates and two units of packed red blood cells. Control thromboelastography showed no changes and the patient was weaned from the bypass uneventfully. Subsequently, the patient was transferred to the intensive care unit (ICU), mechanically ventilated under sedation with propofol $4 \mathrm{mg} /$ $\mathrm{kg} / \mathrm{h}$, on pressure regulated volume control mode (PRVC) with tidal volume $7 \mathrm{~mL} / \mathrm{kg}$, respiratory rate $18 /$ minute, positive end-expiratory pressure (PEEP) $5 \mathrm{~cm} \mathrm{H}_{2} \mathrm{O}, \mathrm{FiO}_{2} 0.50$, under vasopressor (noradrenaline $0.46 \mu \mathrm{g} / \mathrm{kg} / \mathrm{min}$ ) and inotropic (dobutamine $12 \mu \mathrm{g} / \mathrm{kg} / \mathrm{min}$ ) support. Arterial blood gas on ICU admission was $\mathrm{pH} 7.45 ; \mathrm{PaCO}_{2} 42 \mathrm{mmHg}, \mathrm{PaO}_{2} 120$ $\mathrm{mmHg}$; $\mathrm{SaO}_{2} 96$ \%; $\mathrm{HCO}_{3} 29 \mathrm{mmol} / \mathrm{L}$; lactate $37 \mathrm{mg} / \mathrm{dL}$.

In the first 24 hours following admission to the ICU, the patient showed electrical and hemodynamic instability with

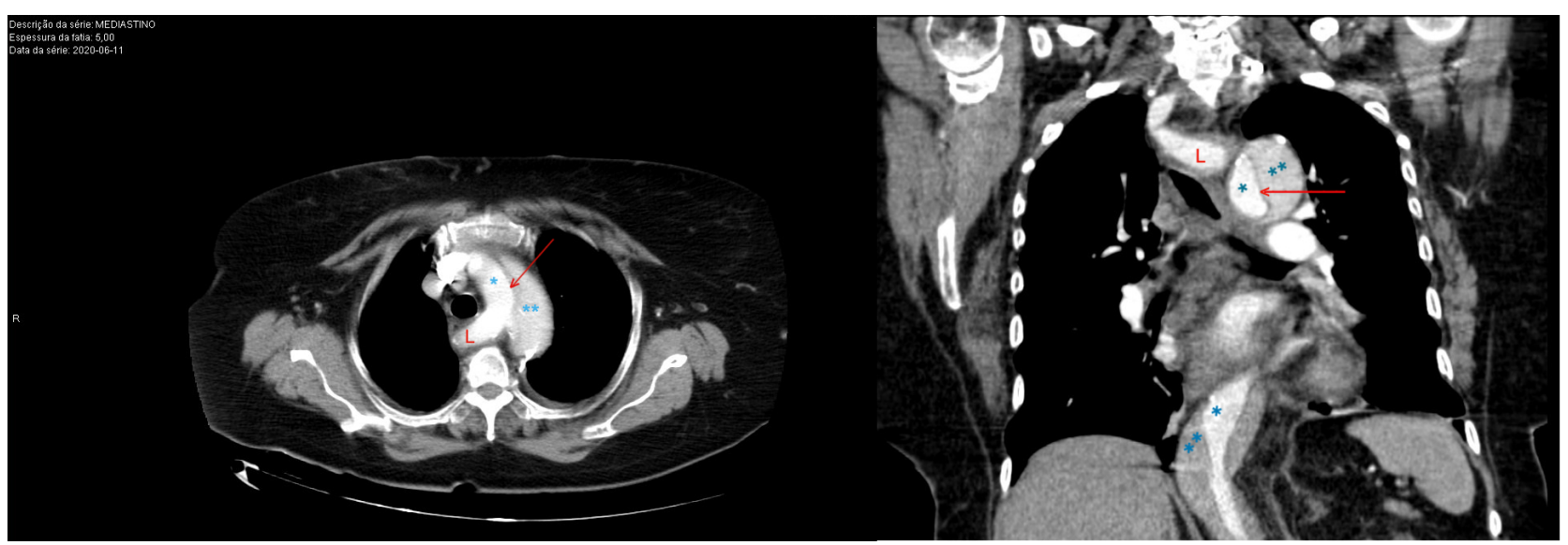

Figure 1: Preoperative thoracic computed tomographic angiography: Acute Stanford type A aortic dissection with intimal flap (arrow) and lusory artery (L).

(*true lumen aorta; **false lumen). 
Citation: Fernandes S, Ribeiro M, Rodrigues M, et al. (2021) Veno-Venous Extracorporeal Membrane Oxygenation Use in Acute Respiratory Distress Syndrome after Acute Stanford Type A Aortic Dissection Repair: A Case Report. J Cardiothorac Surg Ther 5(1):98-102

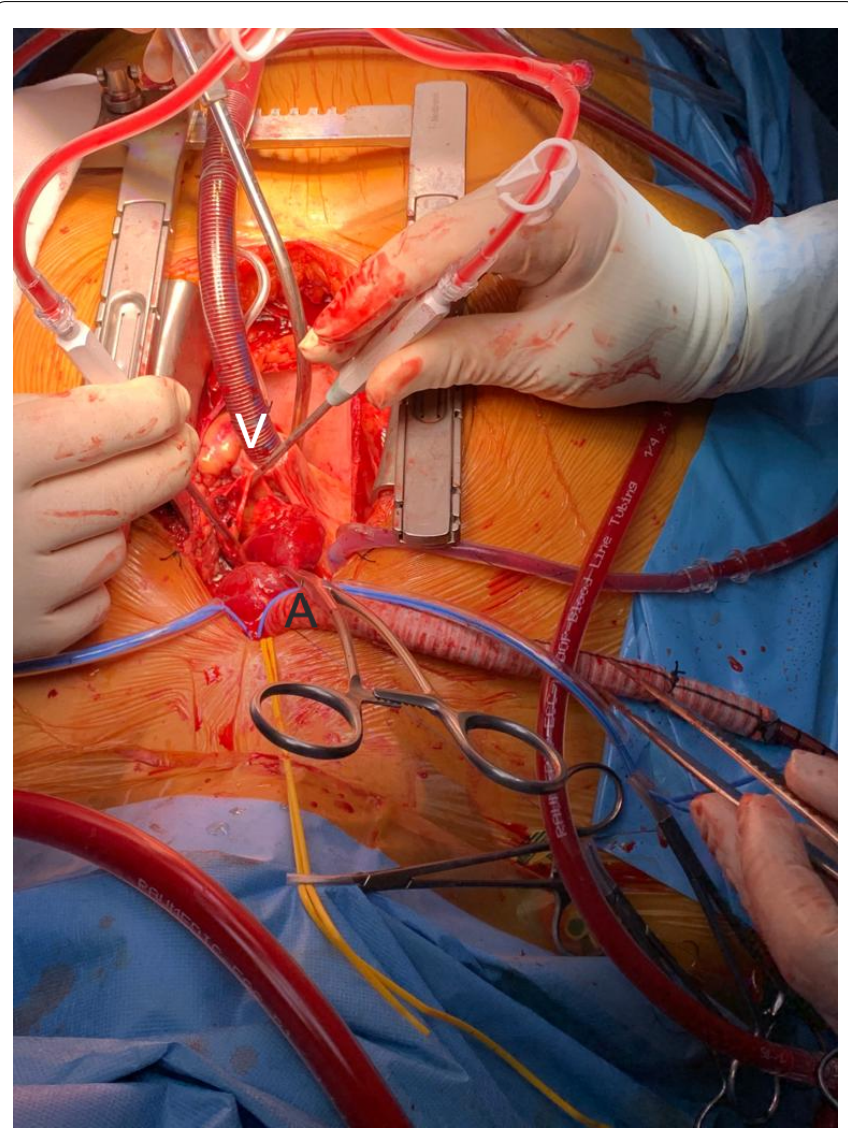

Figure 2: Intraoperative cannulation with right common carotid artery cannulation $(\mathrm{A})$ and right atrium appendage venous cannulation (V).

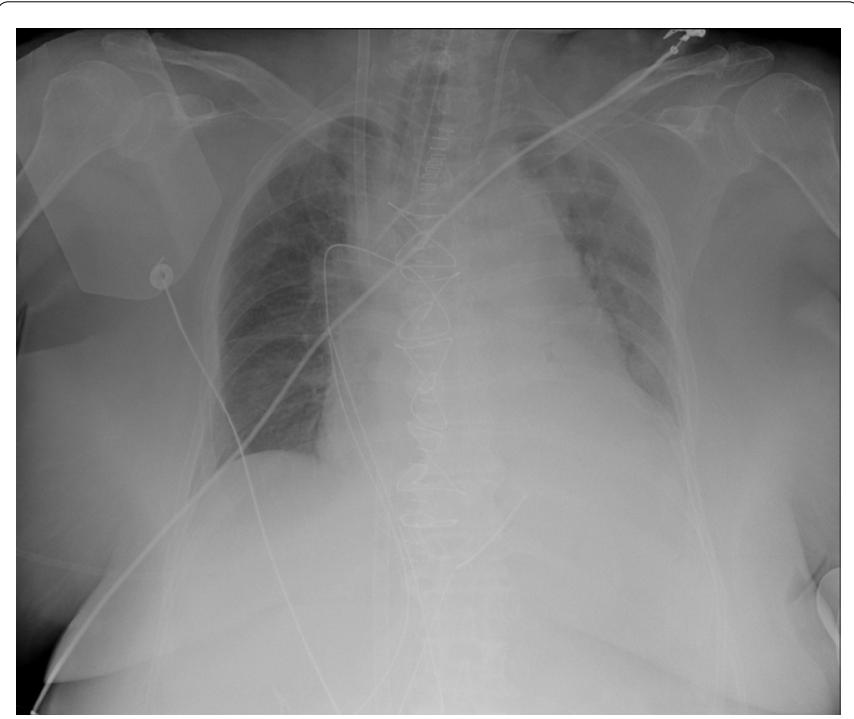

Figure 3: Chest $\mathrm{X}$-ray showing ARDS, orotracheal tube, chest drains, left internal jugular central venous line and VV-ECMO cannulas.

atrial fibrillation with rapid ventricular response and profound hypoxemia $\left(\mathrm{SaO}_{2} 90 \% ; \mathrm{PaO}_{2} 69 \mathrm{mmHg}\right)$, despite protective ventilation. Regardless of optimal medical strategies, the patient was progressively unstable with respiratory and cardiovascular dysfunction. Arterial blood gas tests gave the following results: $\mathrm{pH} 7.42, \mathrm{PaCO}_{2} 34.5 \mathrm{mmHg}, \mathrm{PaO}_{2} 58 \mathrm{mmHg}$,
$\mathrm{HCO}_{3} 24 \mathrm{mmol} / \mathrm{L}, \mathrm{SaO}_{2} 91.5 \%$ and lactate $17.0 \mathrm{mg} / \mathrm{dL}$. Our first primary hypothesis was pulmonary embolism which was excluded after chest CT angiography, suggesting severe ARDS from multi factorial causes.

The patient was maintained sedated with propofol $(3.0 \mathrm{mg} / \mathrm{kg} / \mathrm{h})$ and remifentanil $(5 \mu \mathrm{g} / \mathrm{kg} / \mathrm{h})$ and received a cisatracurium perfusion ( $2 \mu \mathrm{g} / \mathrm{kg} / \mathrm{min}$ ); PEEP was increased to $15 \mathrm{~cm} \mathrm{H} \mathrm{H}_{2} \mathrm{O}$ with no oxygenation improvement during the next 16 hours. Since she could not be subjected to prone positioning, it was decided to start respiratory support with VV-ECMO (Figure 3). A double cannulation was performed with bi-caval dual-lumen cannula through the right internal jugular vein and left femoral vein using a $15 \mathrm{Fr}(15 \mathrm{~cm})$ catheter and a $23 \mathrm{Fr}(55 \mathrm{~cm})$ catheter, respectively. The Quadrox oxygenator and Rotaflow pump (Getinge Group ${ }^{\circledR}$, Gothenburg, Sweden) were used to provide ECMO support. Pump flow was $4.0 \mathrm{~L} /$ minute and pump speed was around 3800 rotation/minute. Ultra-protective lung ventilation with $4 \mathrm{~mL} / \mathrm{kg}$ of predicted body weight, maintaining driving pressure of 10 to $25 \mathrm{mmHg}$, minimizing a high fraction of inspired oxygen, and maintaining PEEP at approximately $8 \mathrm{~cm}$ $\mathrm{H}_{2} \mathrm{O}$ and strict fluid balance was practiced. Anticoagulation was sustained with unfractionated heparin infusion (6.5 U/ $\mathrm{kg} / \mathrm{h}$ ) with a goal of an aPTT ratio of 1.5 .

In the following days, the gas exchange and chest- $X$ ray gradually improved. Despite respiratory improvement, the patient evolved with oliguric acute renal failure and refractory metabolic acidosis, requiring continuous venovenous hemodiafiltration (CVVHDF).

VV-ECMO and CVVHDF were weaned off on day 11 and 12, respectively. No major bleeding or thrombotic complications developed. She recovered renal function and became hemodynamically more stable. Invasive mechanical ventilation weaning was a difficult process because of ICU-acquired weakness for which she was subjected to early mobilization and exercise training (physiotherapy and respiratory care). She was weaned from mechanical ventilation and extubated on day 20. There were no neurological complications.

The patient's total ICU stay was 23 days. She was transferred to the surgical ward on $3^{\text {rd }}$ July, but readmitted to ICU from $12^{\text {th }}$ to $16^{\text {th }}$ July due to septic shock from a urinary infection caused by Klebsiella pneumoniae. She received 7 days of empirical antibiotic therapy with meropenem. Repeated urine and blood cultures were negative. On $6^{\text {th }}$ August, she was discharged to a long-term care facility for further rehabilitation. Chest X-ray improved consistently (Figure 4). After 6 months, she is alive and receiving rehabilitation.

The authors are accountable for all aspects of the work in ensuring that questions related to the accuracy or integrity of any part of the work are appropriately investigated and resolved. All procedures performed in studies involving human participants were in accordance with the ethical standards of the institutional and national research committee and with the Helsinki Declaration (as revised in 2013). Written informed consent was obtained from the patient. 
Citation: Fernandes S, Ribeiro M, Rodrigues M, et al. (2021) Veno-Venous Extracorporeal Membrane Oxygenation Use in Acute Respiratory Distress Syndrome after Acute Stanford Type A Aortic Dissection Repair: A Case Report. J Cardiothorac Surg Ther 5(1):98-102

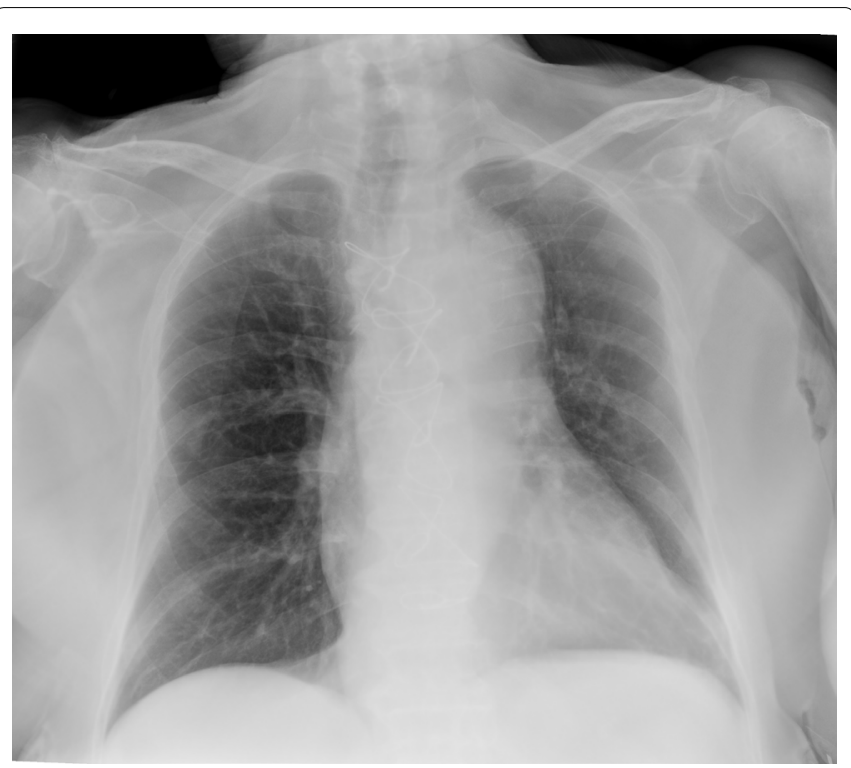

Figure 4: Chest X-ray at hospital discharge (6 $6^{\text {th }}$ August).

\section{Discussion}

Acute aortic dissection is one of the most common aortic catastrophes with extremely high morbidity and mortality rates. The mortality rate of acute Stanford type $A$ aortic dissection approaches $26 \%$ with surgical therapy, and has dropped to $12 \%$ during the last decade due to surgical advances and improved postoperative management $[13,14]$.

During the surgical treatment of Stanford type A aortic dissection, a temporary block of the systemic circulation, cerebral selective perfusion and deep hypothermic cardiopulmonary arrest to address arch involvement are required. Despite the application of improved surgical techniques, the risk of postoperative organ dysfunction persists.

The incidence of ARDS following aortic surgery has been reported as high as 12.7 to $20 \%$ [3-8]. This risk is higher in emergent procedures and the mortality rate can be as high as $80 \%[15,16]$. Many factors contribute to hypoxemia after aortic dissection surgery due to damage to pulmonary capillary endothelial cells and alveolar epithelial cells. Systemic and local inflammatory reactions after aortic vascular tissue destruction with release of massive amounts of inflammatory mediators along with extracorporeal circulation, surgical trauma, ischemia-reperfusion injury with aortic clamping and unclamping, circulatory arrest, systemic hypothermia and perioperative blood transfusion are responsible for ARDS [17-19]. Further, hypoxic pulmonary vasoconstriction is inhibited, resulting in ventilation/perfusion mismatching and shunting, prolonging postoperative mechanical ventilation and increasing mortality [19].

Effective medical interventions are limited and controversial. The management of lung injury in these patients still remains a significant challenge. Mechanical ventilation alone cannot maintain the respiratory function. On the other hand, the therapeutic strategies to control pulmonary damage are limited in some instances, such as prone positioning in postoperative cardiac surgery. The main approach is the use of protective ventilation. However, in some patients with severe ARDS, adequate oxygenation is impossible to obtain with protective ventilation strategies. In these cases, ECMO can be a reasonable option, considering the progressive comorbidities (ischemic cardiopathy), allowing to minimize the lung injury as well as achieving adequate oxygenation.

Although the use of VA-ECMO has been extensively studied in post cardiac surgery patients, the literature on the use of VV-ECMO is far more limited [9-12]. In patients with pulmonary repercussion alone, without cardiovascular dysfunction, the use of VV-ECMO can prove a feasible solution without many of the inconveniencies of VA-ECMO, such as an increased risk of bleeding, stroke, renal failure or differential hypoxia from maldistribution of oxygen. Nakamura, et al. presented a series of 11 patients with a survival rate of $63.6 \%$ to hospital discharge and the non-survivors were significantly older $(p<0.01)$ [9]. Song, et al. presented a series of 13 patients with a survival rate of $53.8 \%$ to hospital discharge with the oldest survivor being 74-years-old [10].

We present the case of a 72-year-old female patient who underwent an acute Stanford type $A$ aortic dissection surgery with extracorporeal circulation who developed severe ARDS, requiring VV-ECMO as rescue therapy after conventional medical management (neuromuscular blockade; increased PEEP) failed to improve oxygenation. Advanced age is described as a relative contraindication [13] to mechanical support with ECMO but there is no consensus in literature regarding a limit. Although the mortality rate is higher in elderly patients, ECMO support can be a valuable therapy in selected patients and can lead to an excellent recovery. Over the last 4-year period in our institution, acute AD repair occurred in 93 patients, with 3 patients evolving to severe ARDS requiring VV-ECMO support.

We describe the successful use of VV-ECMO in post cardiac surgery ARDS, and it supports all the recently published reports that show VV-ECMO as a feasible bridging therapy in severe refractory ARDS after cardiac surgery under extracorporeal circulation. Preventing postoperative ARDS is therefore particularly important in these patients.

\section{Conflicts of Interest}

The authors have no conflicts of interest to declare.

\section{Sources of Funding}

None.

\section{References}

1. Pape LA, Awais M, Woznicki EM, et al. (2015) Presentation, diagnosis, and outcomes of acute aortic dissection: 17-year trends from the international registry of acute aortic dissection. J Am Coll Cardiol. 66:350-358.

2. Nienaber CA, Clough RE (2115) Management of acute aortic dissection. Lancet 385:800-811.

3. Chen MF, Chen LW, Cao H, et al. (2016) Analysis of risk factors for and the prognosis of postoperative acute respiratory distress syndrome in patients with Stanford type A aortic dissection. J Thorac Dis 8: 2862-2871. 
Citation: Fernandes S, Ribeiro M, Rodrigues M, et al. (2021) Veno-Venous Extracorporeal Membrane Oxygenation Use in Acute Respiratory Distress Syndrome after Acute Stanford Type A Aortic Dissection Repair: A Case Report. J Cardiothorac Surg Ther 5(1):98-102

4. Su IL, Wu VC, Chou AH, et al. (2019) Risk factor analysis of postoperative acute respiratory distress syndrome after type $A$ aortic dissection repair surgery. Medicine (Baltimore) 98: e16303.

5. Kurabayashi M, Okishige K, Azegami K, et al. (2010) Reduction of the $\mathrm{PaO} 2 / \mathrm{FiO} 2$ ratio in acute aortic dissection - relationship between the extent of dissection and inflammation. Circ J 74: 2066-2073.

6. Luo F, Zhou XL, Li JJ, et al. (2009) Inflammatory response is associated with aortic dissection. AgeingRes Rev 8: 31-35.

7. Apostolakis E, Filos KS, Koletsis E, et al. (2010) Lung dysfunction following cardiopulmonary bypass. J Card Surg 25: 47-55.

8. Stephens RS, Shah AS, Whitman GJ (2013) Lung injury and acute respiratory distress syndrome after cardiac surgery. Ann Thorac Surg 95: 1122-1129.

9. Nakamura H, Yamaguchi H, Amano A (2013) Venovenous extracorporeal membrane oxygenation is effective against post-cardiotomy acute respiratory failure in adults. Gen Thorac Cardiovasc Surg 61: 402-408.

10. Song JH, Woo WK, Song SH, et al. (2016) Outcome of venovenous extracorporeal membrane oxygenation use in acute respiratory distress syndrome after cardiac surgery with cardiopulmonary bypass. J Thorac Dis 8: 1804-1813.

11. Volpi S, Sertic F, Valchanov K, et al. (2019) Use veno-venous extra corporeal membrane oxygenation in elderly patients with postcardiotomy hypoxia: The changing paradigm of respiratory support in adult respiratory distress syndrome. J Cardiothorac Surg 14: 10.
12. Kono, T, Oda T, Akaiwa K, et al. (2017) Veno-venous extracorporeal membrane oxygenation for acute lung injury after surgery for aortic dissection: A case report. World Journal of Cardiovascular Surgery 7: 156-163.

13. Conway BD, Stamou SC, Kouchoukos NT, et al. (2014) Improved clinical outcomes and survival following repair of acute type $A$ aortic dissection in the current era. Interact Cardiovasc Thorac Surg 19: 971-976.

14. Omura A, Miyahara S, Yamanaka K, et al. (2016) Early and late outcomes of repaired acute DeBakey type I aortic dissection after graft replacement. J ThoracCardiovascSurg 151: 341-348.

15. Fernandez-Perez ER, Sprung J, Afessa B, et al. (2009) Intraoperative ventilator settings and acute lung injury after elective surgery: A nested case control study. Thorax 64: 121 127.

16. Milot J, Perron J, Lacasse $Y$, et al. (2001) Incidence and predictors of ARDS after cardiac surgery. Chest 119: 884-888.

17. Weissman C (2004) Pulmonary complications after cardiac surgery. Semin Cardiothorac Vasc Anesth 8: 185-211.

18. Vlaar AP, Hofstra JJ, Determann RM, et al. (2011) The incidence, risk factors, and outcome of transfusion-related acute lung injury in a cohort of cardiac surgery patients: A prospective nested case-control study. Blood 117: 4218-4225.

19. Apostolakis EE, Koletsis EN, Baikoussis NG, et al. (2010) Strategies to prevent intraoperative lung injury during cardiopulmonary bypass. J Cardiothorac Surg 5:1.

DOI: $10.36959 / 582 / 435$

Copyright: (c) 2021 Fernandes S. This is an open-access article distributed under the terms of the Creative Commons Attribution License, which permits unrestricted use, distribution, and reproduction in any medium, provided the original author and source are credited. 